\title{
Multimodal intervention program to improve hand hygiene compliance: effectiveness and challenges
}

\author{
Sihem Ben Fredj ${ }^{1 *}$, Asma Ben Cheikh ${ }^{1,3}$, Sana Bhiri ${ }^{1,3}$, Hela Ghali ${ }^{1}$ Salwa Khefacha ${ }^{1}$, Lamine Dhidah,3, \\ Latifa Merzougui ${ }^{2,3}$, Mohamed Ben Rejeb $b^{1,3}$ and Houyem Said Latiri ${ }^{1,3}$
}

\begin{abstract}
Background: Hand hygiene $(\mathrm{HH})$ is considered the most important measure to tackle the transmission of healthcare-associated pathogens. However, compliance with recommendations is usually low and effective improvement strategies are needed. We aimed to assess the effectiveness of an intervention targeting hand hygiene promotion among healthcare workers (HCWs).
\end{abstract}

Methods: We conducted a pre-post interventional study design in the university hospital Sahloul, Sousse, Tunisia, from January 2015 to December 2016. The intervention program consisted of training sessions and distribution of posters of hand hygiene guidelines. To assess the evolution of HH observance at pre- and post-intervention, the same observation form was distributed and collected at healthcare workers' workplace.

Results: Of the 1201 and 1057 opportunities for hand hygiene observed among all categories of HCWs, overall compliance enhanced significantly from 32.1 to $39.4 \%(p<0.001)$ respectively at pre- and post-intervention. Nurses were the most compliant with a significant improvement from 34.1 to $45.7 \%(p<0.001)$ respectively at pre- and post-intervention. Furthermore, analysis by department showed significant improvement of compliance in orthopedic department $(p<0.001)$, maxillofacial-surgery department $(p<0.001)$, pediatrics department $(p=0.013)$, and emergencies $(p=0.038)$.

Conclusion: This study showed the feasibility and effectiveness of a health-setting-based intervention to enhance hand hygiene observance in the context of a developing country.

Keywords: Hand hygiene, Compliance, Intervention

\section{Background}

In Tunisia, several studies have uncovered the alarming fact that up to $17 \%$ of inpatients develop healthcareassociated infections (HAIs) [1-3]. Patients sustaining a HAI compared with those who do not, have significantly higher morbidity, mortality, and length of stay [4-6]. That vicious circle of uncontrolled speeding up of HAIs and increasing financial losses would ultimately weaken healthcare systems especially in low- and middle-income

\footnotetext{
* Correspondence: sihembenfredj2015@gmail.com

${ }^{1}$ Department of Prevention and Care Safety, University Hospital Sahloul, 4011

Sousse, Tunisia

Full list of author information is available at the end of the article
}

countries, where little data are available. In developed countries, these infections costs an additional $€ 7$ billion per year in Europe, considering direct costs only [7] and USA $\$ 6.5$ billion annually for the care of inpatients in the USA [8]. This alarming global burden is avoidable. It is well established that the hands of healthcare workers (HCWs) are the main way of pathogen transmission from one patient to another and within the healthcare environment during the healthcare delivery $[9,10]$. Therefore, the key element in interruption of the HAIs spread is sustainable hand hygiene (HH). Evidence-based models and prospective studies backed the importance of $\mathrm{HH}$ adherence to decrease the HAIs occurrence and to improve the patient 
outcome [11]. However, HCWs usually comply poorly with recommendations particularly in settings with limited resources reflecting a gap between evidence and real practice [12]. Amazian et al. demonstrated that compliance with hand hygiene varied greatly between countries and settings but was globally low (27\%) in 22 hospitals in four Mediterranean countries. The $\mathrm{HH}$ compliance rates were $52.8 \%$, $32.3 \%, 18.6 \%$, and $16.9 \%$, respectively for Egypt, Tunisia, Algeria, and Morocco [13].

Promotion of effective measures to enhance $\mathrm{HH}$ adherence is a core component of the WHO initiative "save lives clean your hands" launched in 2009 in order to improve patient safety [14]. Thereby, WHO developed a multimodal implementation strategy and measures for hand hygiene [15] which proved its effectiveness and adaptability to different healthcare settings with different cultures, local specificities, and habits [16-23]. Our study aimed to demonstrate the feasibility and effectiveness of a health-setting intervention targeting hand hygiene promotion based on the WHO multimodal strategy in all the wards of University Hospital Center Sahloul in Sousse, Tunisia.

\section{Methods}

\subsection{Setting}

The study was conducted at the University Hospital Center (UHC) of Sahloul in eastern Sousse, Tunisia. It is a 690-bed tertiary-level teaching hospital with ten medical departments, ten surgical departments, and three laboratories. It is supported by 1141 healthcare professionals; among them are 173 physicians and 647 paramedical staff.

\subsection{Sample for study}

Target population was all HCW categories (physicians, nurses, and housekeeping staff) agreeing to participate.
All hospital departments were included except for operating theaters, laboratories, and administrative units. The included departments were the Medical Intensive Care Unit, Surgical Intensive Care Unit, departments of General Surgery, Internal Medicine, Cardiology, Orthopedics, Physical Medicine, Nephrology, Gastrology, Cardio-vascular and Thoracic Surgery, Maxillofacial Surgery, Dental Medicine, Neurology, Emergencies, Neurosurgery, Urology, and Pediatrics department.

According to the WHO recommendations for sample size determination [24], the minimal sample size required was 992 observations. The required number of opportunities to be observed was at both time periods, and based on an improvement in the hand hygiene compliance of $10 \%$ between the pre and post intervention. To compensate for possible nonresponse, a total of 1190 observations were planned for the study.

\subsection{Study design}

This study adopted a pre-post interventional study design with one group of HCWs working in all the departments of UHC Sahloul, Sousse, from January 2015 to December 2016. It was designed and reported according to the WHO hand hygiene improvement strategy [15], which has been implemented and succeeded in many institutions across the world [23]. We adapted the strategy as per our institution organizational characteristics (Fig. 1). The global approach was based on the following 4 steps [25].

\subsubsection{Step 1, preparedness}

Two months prior to the first evaluation of $\mathrm{HH}$ compliance, the Department of Prevention and Care Safety ensured the institution preparedness by providing the necessary resources, making available alcohol-based hand rub at the point of care, reviewing the main issues,

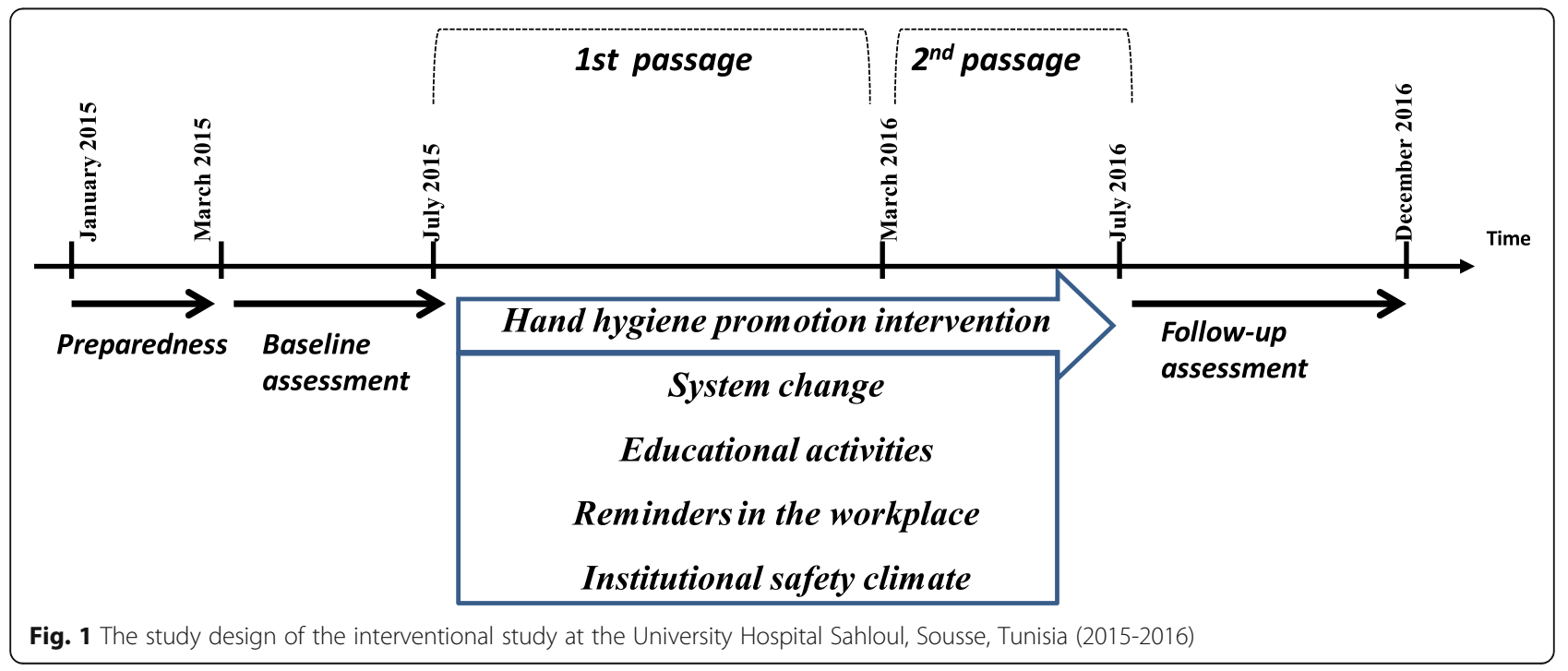


and clarifying the plan schema of the strategy. For that, we informed all departments' heads and the general director of the hospital about the study.

\subsubsection{Step 2, baseline assessment}

The research team conducted a pre-intervention baseline assessment of $\mathrm{HH}$ compliance during 2 months. The trained data collectors observed directly the selected professionals, for $2 \mathrm{~h}$ daily during the morning shift. Each observation was broken down into sessions of 20 min distributed equally throughout the study duration. HCWs were not informed about neither the actual goal of the observations nor the schedule of the observations' time. They were not aware of when exactly these observations were being made.

\subsubsection{Step 3, intervention}

The intervention program was launched in step 3.

The intervention program started in January 2016 and lasted 7 months. It comprised two periods of passages in order to reinforce the educational program for hand hygiene promotion. The intervention strategy was based on the key components of the WHO multimodal strategy [25]:

2.3.3.1 System change We used a checklist to review once a month the availability of alcohol-based hand rub, the liquid soap, washbasins, washbasins/bed ratio, and hand towels for single use. Alcohol-based hand rub, liquid soap, and towels were distributed at points of patient care not available. The damaged where they were washbasins were either fixed or replaced.

2.3.3.2 Educational activities The implementation approach of the training program was based on the WHO tools for $\mathrm{HH}$ promotion [26]. Whereby, we rolled out open sensitization days, educational sessions, showing educational films followed by interactive discussion and presentation of the pre-intervention results. We delivered an attendance certificate for encouraging HCWs to participate in the workshops. These different methods targeted an awareness-raising about the burden of the hospital acquired infections (e.g., morbidity, mortality, and costs), the concept of $\mathrm{HH}$ and its key role in the prevention of hospital acquired infections and the correct techniques of $\mathrm{HH}$.

2.3.3.3 Reminders in the workplace $\mathrm{HH}$ leaflets were distributed to each department and posters were bonded in strategic areas of the hospital departments. They included key messages and emphasized the $\mathrm{HH}$ importance as the cornerstone of infection control. They also showed the techniques of hand washing with soap and water or cleaning with alcohol-based hand rub.
2.3.3.4 Institutional safety climate We introduced a compelling communication to motivate the stakeholders to be involved in creating an environment that promotes and encourages patient safety. We were seeking to get the support of all HCWs. Therefore, we tried to obtain a formal and clear commitment from the senior hospital managers for the promotion of $\mathrm{HH}$ in order to maximize the HCWs involvement in this project.

\subsubsection{Step 4, post-intervention assessment}

This step consisted of the follow-up and feedback period. The post-intervention evaluation of the $\mathrm{HH}$ compliance was continued.

\subsection{Definition of terms}

Five indications/moments for $\mathrm{HH}$ are based on those defined by the $\mathrm{WHO}$ guidelines [27].

A moment or indication is when there is a perceived or actual risk of pathogen transmission from one surface to another via the HCWs hands (gloved or ungloved) while undertaking a succession of tasks [28].

According to the WHO guidelines, the hands should be washed with soap or rubbed with alcoholic disinfectant [29]:

Moment 1: before patient contact

Moment 2: before a procedure or an aseptic task

Moment 3: after a body fluid exposure risk

Moment 4: after touching a patient

Moment 5: after touching patient surroundings

Opportunity for $\mathrm{HH}$ is a situation whenever one of the moments for hand hygiene is present and observed during patient care. Two indications for $\mathrm{HH}$ may co-occur for one opportunity.

Compliance with $\mathrm{HH}$ was defined as either washing the hands (gloved or ungloved) with water and plain soap or rubbing the hands with an antiseptic solution when an opportunity occurred. Departure from the room after patient care without $\mathrm{HH}$ and failure to remove gloves after patient contact or contact between a dirty and a clean body site on the same patient were considered noncompliance [30]. $\mathrm{HH}$ compliance, the main outcome measure, was calculated as the proportion of $\mathrm{HH}$ indications for which $\mathrm{HCW}$ performed a correct action [31]:

$\mathrm{HH}$ compliance $=\frac{\text { number of acts of } \mathrm{HH} \text { when the indication exists } \times 100}{\text { total number of } \mathrm{HH} \text { opportunities }}$

\subsection{Instruments of measurement}

We assessed HCWs adherence to $\mathrm{HH}$ guidelines at pre and 6-months post-intervention with a validated tool. It was constructed by the WHO [31], and composed of five parts. The first part was about the general information 
of the study setting and sessions' execution. The second part included the professional's category, the indication, and the $\mathrm{HH}$ action whether it was a hand washing, alcohol-based hand rub, or no action was taken. Wearing gloves was considered to be no action.

\subsection{Data analysis}

Statistical analysis was carried out using the program SPSS v. 21 software for windows. The absolute and relative frequencies were given for the qualitative variables. Proportions were compared by using chi-square tests to compare the $\mathrm{HH}$ compliance among HCWs according to their categories, specialties, and departments. Multiple logistic regression analysis was used in order to seek potential determinants of $\mathrm{HH}$ compliance. The adjusted odds ratios (aOR) and 95\% confidence interval (CI95\%) were calculated. The significance level was set at 0.05 .

\section{Results}

A total number of 2258 opportunities for $\mathrm{HH}$ were observed, 1201 at the baseline assessment and 1057 opportunities in the 2 months of observation that followed.

Overall compliance enhanced significantly from 32.1 at baseline to $39.4 \%(p<0.001)$ at follow-up. We observed striking differences in the level of compliance among the three professional categories. Markedly improved adherence was recorded among nurses. Their compliance improved significantly from 34.1 to $45.7 \%$ ( $p$ $<0.001$ ) respectively at pre- and post-intervention. $\mathrm{HH}$ compliance among doctors decreased insignificantly from 30.7 in 2015 to $23.1 \%$ in $2016(p=0.06)$. Housekeeping staff recorded the lowest $\mathrm{HH}$ compliance which dropped from 19.8 to $16.1 \%$ (Table 1 ).

Improvement was observed across all medical specialties. In medicine, $\mathrm{HH}$ compliance averaged $29.3 \%$ at pre-

Table 1 Hand hygiene compliance among health care professionals, before and after intervention, at University Hospital Sahloul, Sousse, Tunisia 2015-2016

\begin{tabular}{|c|c|c|c|c|c|}
\hline \multirow[b]{2}{*}{ Subgroups } & \multicolumn{2}{|l|}{ Pre-intervention } & \multicolumn{2}{|l|}{ Post-intervention } & \multirow{2}{*}{$\begin{array}{l}\boldsymbol{p} \\
\text { value }\end{array}$} \\
\hline & Compliance $\boldsymbol{n}(\%)$ & C195\% & Compliance $\boldsymbol{n}(\%)$ & $\mathrm{C} 195 \%$ & \\
\hline Overall & $385(32.1)$ & $29.5-34.8$ & $416(39.4)$ & $36.4-42.3$ & $<10^{-3}$ \\
\hline \multicolumn{6}{|l|}{ Professional category } \\
\hline Nurses & $269(34.1)$ & $30.8-37.5$ & $355(45.7)$ & $42.2-49.3$ & $<10^{-3}$ \\
\hline Physicians & 99 (30.4) & $25.7-36.0$ & $52(23.1)$ & $17.8-29.2$ & 0.06 \\
\hline Housekeeping staff & $17(19.8)$ & $12.3-29.1$ & $9(16.1)$ & $8.1-27.4$ & 0.57 \\
\hline \multicolumn{6}{|l|}{ Medical speciality } \\
\hline Intensive Care & $197(41.4)$ & $36.2-45.1$ & $129(48.9)$ & $42.7-55.0$ & 0.029 \\
\hline Surgery & $63(20.9)$ & $16.8-26.3$ & $158(34.6)$ & $30.2-39.1$ & $<10^{-3}$ \\
\hline Medicine & $107(29.3)$ & $24.7-34.3$ & $110(36.2)$ & $30.7-41.7$ & 0.05 \\
\hline Emergency & $18(36.0)$ & $23.2-50.8$ & $19(59.4)$ & $40.7-75.7$ & 0.038 \\
\hline \multicolumn{6}{|l|}{ Department } \\
\hline Nephrology & $22(31.4)$ & $21.1-43.7$ & $5(9.6)$ & $3.5-21.7$ & 0.004 \\
\hline Physical Medicine & $15(16.5)$ & $9.8-26.0$ & $10(18.2)$ & $9.5-31.3$ & 0.79 \\
\hline Urology & $10(24.4)$ & $12.9-40.6$ & $22(24.4)$ & $16.2-34.8$ & 0.99 \\
\hline Neurology & $17(37.0)$ & $23.5-52.4$ & $10(31.3)$ & $15.7-50.1$ & 0.60 \\
\hline General Surgery & $13(24.1)$ & $13.9-37.9$ & $21(33.3)$ & $22.2-46.4$ & 0.27 \\
\hline Cardiology & $30(35.3)$ & $25.4-46.4$ & $33(35.1)$ & $25.7-45.7$ & 0.98 \\
\hline Orthopedics & $4(7.0)$ & $2.2-17.8$ & $48(37.8)$ & $29.4-46.8$ & $<10^{-3}$ \\
\hline Surgical Intensive Care & $56(35.7)$ & $28.3-43.7$ & $31(37)$ & $26.8-48.1$ & 0.85 \\
\hline Gastrology & $24(29.6)$ & $20.2-40.9$ & $13(40.6)$ & $24.2-59.2$ & 0.26 \\
\hline Neurosurgery & $11(26.8)$ & $14.7-43.2$ & $24(45.3)$ & $31.8-59.4$ & 0.06 \\
\hline Maxillofacial Surgery & $2(4.3)$ & $0.7-15.7$ & $28(46.7)$ & $33.8-59.9$ & $<10^{-3}$ \\
\hline Internal Medicine & $25(36.8)$ & $25.6-49.3$ & $17(51.5)$ & $33.8-68.8$ & 0.15 \\
\hline Thoracic and Cardiovascular Surgery & $28(41.2)$ & $29.5-53.7$ & $34(53.1)$ & $40.3-65.5$ & 0.17 \\
\hline Medical Intensive Care & $36(38.7)$ & $28.9-49.4$ & $15(50.0)$ & $31.6-68.3$ & 0.27 \\
\hline Pediatrics & $58(47.2)$ & $38.1-56.3$ & 78 (63.0) & $53.7-71.2$ & 0.013 \\
\hline Dental Medicine & $16(55.2)$ & $35.9-72.3$ & $8(25.0)$ & $12.1-43.7$ & 0.016 \\
\hline
\end{tabular}


intervention and $36.2 \%$ at post-intervention. In surgery, $\mathrm{HH}$ compliance averaged $20.9 \%$ at pre-intervention and $34.6 \%$ at post-intervention. The intensive care units, whether they were medical or surgical, had the highest compliance rate in the two periods of the study (Table 1).

Furthermore, analysis by department indicated significant improvement of $\mathrm{HH}$ compliance from baseline to the intervention period within the majority of hospital departments. It increased significantly in the orthopedic department from 7 to $37.8 \%(p<0.001)$, in the maxillofacial surgery department from 4.3 to $46.7 \%(p<0.001)$, in the pediatric ward from 47.2 to $63 \%(p=0.013)$, and in the emergency department from 36 to $59.4 \%(p=$ 0.016). Nevertheless, HH compliance declined significantly in nephrology department from 31.4 to $9.6 \%(p<$ $\left.10^{-3}\right)$.

$\mathrm{HH}$ compliance was enhanced across all indications for $\mathrm{HH}$; however, it was only significant for "before aseptic task" (Table 2).

After adjusting all variables to each other in a logistic regression analysis model, the study showed that HCWs were more significantly $(\mathrm{aOR}=1.34$, CI95\% 1.11-1.62) compliant after the $\mathrm{HH}$ intervention; nurses were significantly $(\mathrm{aOR}=2.03, \mathrm{CI} 95 \% 1.66-2.49)$ more compliant compared with physicians and other HCWs; compliance was more significant in the indication before aseptic task $(\mathrm{aOR}=1.56$, CI95\% 1.25-1.94) $($ Table 3$)$.

\section{Discussion}

As far as we know, this study was the first to report the implementation of the WHO hand hygiene improvement strategy using a multifaceted approach in a Tunisian healthcare setting. At baseline, $\mathrm{HH}$ compliance (31.6\%) of HCWs in the university hospital of Sahloul was comparable to that shown in the literature [18, 32-34]. However, it was still far from other results [20, 35, 36]. Remarkably, the intervention program resulted in a significant improvement in $\mathrm{HH}$ compliance which reached the $39.4 \%$ in post- assessment. However, the improvement was observed only among nurses, and a slight decrease in $\mathrm{HH}$ compliance was recorded among physicians. Similarly to most studies, the nurses showed a higher $\mathrm{HH}$ compliance than did the other professionals [19, 37-39]. In the present study, the poor $\mathrm{HH}$ adherence among physicians comparing to nurses may be explained by the limited attendance of doctors in training sessions. Hence, making changes to $\mathrm{HH}$ adherence is challenging in our context, particularly to face defective behaviors and routines that may be already established with HCWs. Although the $\mathrm{HH}$ is a simple act to do and a core component in infection control, it seems that it is hardly incorporated into clinical practice especially that physicians showed no significant change in $\mathrm{HH}$ compliance [40]. This phenomenon would be the consequence of potential interferences that impede the best $\mathrm{HH}$ practice [41]. The behavioral determinants were conceptualized as two themes by Maura et al. in a systematic qualitative literature review, according to a theoretical background. The first component was the motivational factors including the social influences, acuity of patient care, self-protection, and use of cues. The second component was the perception of the work environment whether it concerns the resources, the knowledge, the information, or the organizational culture [42]. The contributing factors could be also classified according to their type: individual or organizational determinants. The individual determinants' concern mainly the perception of HAIs risk [43], the knowledge and skill gap [40] or else the forgetfulness [44], dermatology problems, and poor acceptance [45] and obviously, HCWs compliance is influenced by senior's role model [46]. Moreover, hand hygiene adherence among HCWs is frequently suboptimal and resistant to improvement as shown by Larson et al. [47]. The organizational determinants could be summarized by the work environment characteristics such as the information accessibility and access to $\mathrm{HH}$ resources, especially at patient bedside [42] and the high workload [30]. In addition, as a developing country, other factors

Table 2 Hand hygiene compliance according to the WHO 5 indications, before and after intervention, at University Hospital Sahloul, Sousse, Tunisia 2015-2016

\begin{tabular}{|c|c|c|c|c|c|c|c|}
\hline \multirow[b]{2}{*}{ Indications for hand hygiene } & \multicolumn{3}{|l|}{ Pre-intervention } & \multicolumn{3}{|l|}{ Post-intervention } & \multirow[b]{2}{*}{$\begin{array}{l}\boldsymbol{p} \\
\text { value }\end{array}$} \\
\hline & $\begin{array}{l}\text { Hand hygiene } \\
\text { opportunitiesn }\end{array}$ & $\begin{array}{l}\text { Compliance } \boldsymbol{n} \\
(\%)\end{array}$ & $\mathrm{Cl} 95 \%$ & $\begin{array}{l}\text { Hand Hygiene } \\
\text { opportunities } \boldsymbol{n}\end{array}$ & $\begin{array}{l}\text { Compliance } \boldsymbol{n} \\
(\%)\end{array}$ & $\mathrm{Cl} 195 \%$ & \\
\hline Before patient contact & 453 & 107 (23.6) & $\begin{array}{l}19.6- \\
27.6\end{array}$ & 340 & $81(23.8)$ & $\begin{array}{l}20.1- \\
29.7\end{array}$ & 0.94 \\
\hline Before aseptic task & 294 & $71(24.1)$ & $\begin{array}{l}19.1- \\
29.1\end{array}$ & 196 & $210(38.1)$ & $\begin{array}{l}34.4- \\
48.5\end{array}$ & 0.01 \\
\hline After body fluid exposure risk & 73 & $34(46.6)$ & $\begin{array}{l}34.9- \\
58.5\end{array}$ & 40 & $20(50.0)$ & $\begin{array}{l}36.8- \\
70.7\end{array}$ & 0.72 \\
\hline After patient contact & 407 & $206(50.6)$ & $\begin{array}{l}44.6- \\
54.5\end{array}$ & 438 & $213(48.6)$ & $\begin{array}{l}44.9- \\
54.5\end{array}$ & 0.56 \\
\hline $\begin{array}{l}\text { After contact with patient } \\
\text { surroundings }\end{array}$ & 158 & $44(27.8)$ & $\begin{array}{l}21.1- \\
35.6\end{array}$ & 83 & $23(27.7)$ & $\begin{array}{l}22.5- \\
42.7\end{array}$ & 0.89 \\
\hline
\end{tabular}


Table 3 Binary logistic regression model of potential factors determining hand hygiene compliance at University Hospital Sahloul, Sousse, Tunisia 2015-2016

\begin{tabular}{lll}
\hline Variable & $\mathrm{aOR}$ & $\mathrm{Cl} 95 \%$ \\
\hline Event & & \\
$\quad$ Pre-intervention & Reference & \\
Post-intervention & 1.34 & $1.11-1.62$ \\
HCWs & & \\
$\quad$ Physicians and other HCWs & Reference & $1.66-2.49$ \\
$\quad$ Nurses & 2.03 & \\
Indications & & \\
$\quad$ Other indications & Reference & $1.25-1.94$ \\
$\quad$ Before aseptic task & 1.56 & \\
\hline
\end{tabular}

aOR adjusted odds ratio, C195\% 95\% confidence interval

should be considered in the implementation of infection control program including costs, procurement constraints, deficient infrastructure, cultural issues, and lack of knowledge [48]. Therefore, a multidimensional approach is the appropriate strategy to face such multiple constraints. However, the high workload was a heavy barrier in our health setting. First, the current personnel number is limited in relation to the growing demand for healthcare [49]. Second, the Tunisian government adopted a rigid strategy in recent years. Accordingly, we face challenges backfilling missing personnel. Third, we noted a mismanagement of the available human resources following the administration laxity in particular after the revolution in 2011. Nevertheless, the overall enhancement of the $\mathrm{HH}$ compliance was promising. Our intervention to positively influence $\mathrm{HH}$ behavior was effective as we hoped. The same trend was observed in most departments. Similar results were shown through literature around the world $[1,10,12,13,15,17$, 29-33] reflecting the ability of multimodal interventions to raise awareness about the $\mathrm{HH}$ importance. However, it was not always the case. Some studies concluded that the intervention does not affect $\mathrm{HH}$ compliance $[50,51]$.

\subsection{Limitations of the study}

Strengths of our study include the participation of all hospital departments, the use of the WHO intervention strategy that is highly reproducible and sufficient time study (beyond 1 year) to demonstrate significant changes. The main limitations of the study were the lack of control group since it was a single-center study and thus, the educational program would have spread easily. Besides, the Hawthorne effect may change the HCW behavior when they are aware of a professional observing them. This phenomenon has the potential to add bias to an outcome.

\section{Conclusion}

Our study revealed the feasibility and effectiveness of a health-setting-based intervention to enhance hand hygiene observance in the context of a developing country. It suggests the need to incorporate the $\mathrm{HH}$ training as a part of the academic course and the professional diploma. A deeper analysis should be performed to further assess the determinant factors of compliance with hand hygiene. Future studies also should determine whether sustainable intervention program could slow the HAI transmission by targeting the $\mathrm{HH}$ compliance and obviously regular maintenance of the medical and paramedic equipment.

Acknowledgements

Not applicable

\section{Authors' contributions}

This project was carried out in collaboration between all authors. Authors $H S L, L D$, and SB contributed to the design of the study research protocol. Author HSL was the principal investigator. Authors HSL, SB, SBF, HG, SK, LM, and MBR coordinated and participated in the intervention program. Authors $S B F, S B$, and $H G$ participated in the coordination of data collection and entry. Authors SBF, ABC, MBR, and HSL participated in the data analysis,

interpretation of results, and the manuscript redaction. All authors read and approved the final manuscript.

\section{Funding}

This work did not receive any financial support.

\section{Availability of data and materials}

The data used to support the findings of this study are available from the corresponding author upon request.

\section{Ethics approval and consent to participate}

Ethical approval for this study was obtained from Ethics Committee of the University Hospital Sahloul in January 2015. We have also obtained an informed verbal consent from participants to participate since the study was a part of hospital infection control program. The ethics committee approved the verbal consent. We sent an information letter to all the heads of the departments and we obtained support from them before starting project activities. Data was anonymized and confidential.

\section{Consent for publication}

Not applicable since the study does not contain any individual person's data in any form (including individual details, images or videos.

\section{Competing interests}

The authors declare that they have no competing interests.

\section{Author details}

${ }^{1}$ Department of Prevention and Care Safety, University Hospital Sahloul, 4011 Sousse, Tunisia. ${ }^{2}$ Department of Epidemiology, University Hospital Ibn El Jazzar, 3100 Kairouan, Tunisia. ${ }^{3}$ Faculty of Medicine of Sousse, University of Sousse, 4000 Sousse, Tunisia.

Received: 25 February 2019 Accepted: 25 February 2020 1.

References

1. Kallel H, Bahoul M, Ksibi H, Dammak H, Chelly H, Hamida CB, et al. Prevalence of hospital-acquired infection in a Tunisian hospital. J Hosp Infect. 2005;59(4):343-7.

2. Mahjoub M, Bouafia N, Cheikh AB, Ezzi O, Njah M. Culture sécurité des patients par la réponse non-punitive à l'erreur et la liberté d'expression des soignants, Patient safety culture based on a non-punitive response to error and freedom of expression of healthcare professionals. Santé Publique. 2016;28(5):641-6.

3. Ben Salem K, El Mhamdi S, Letaief M, Bchir M, Soltani MS. Epidemiological profile of health-care-associated infections in the central-east area of Tunisia. East Mediterr Health J. 2011;17(6):485-9. 
4. Rejeb MB, Sahli J, Chebil D, Khefacha-Aissa S, Jaidane N, Kacem B, Hmouda H, Dhidah L, Said-Latiri H, Naija W. Mortality among patients with nosocomial infections in tertiary intensive care units of Sahloul hospital, Sousse, Tunisia. Arch Iran Med. 2016;19(3):179-85.

5. Prowle JR, Echeverri JE, Ligabo EV, Sherry N, Taori GC, Crozier TM, et al. Acquired bloodstream infection in the intensive care unit: incidence and attributable mortality. Crit Care Lond Engl. 2011;15(2):R100.

6. Barrasa-Villar Jl, Aibar-Remón C, Prieto-Andrés P, Mareca-Doñate R, MolinerLahoz J. Impact on morbidity, mortality, and length of stay of hospitalacquired infections by resistant microorganisms. Clin Infect Dis. 2017;65(4): 644-52.

7. Annual epidemiological report on communicable diseases in Europe 2008 Report on the state of communicable diseases in the EU and EEAVEFTA countries. Stockholm, European Centre for Disease Prevention and Control, 2008.

8. Klevens RM, Edwards JR, Richards CL, Horan TC, Gaynes RP, Pollock DA, et al. Estimating health care-associated infections and deaths in U.S. hospitals, 2002. Public Health Rep Wash DC 1974. 2007;122(2):160-6.

9. Pittet D, Allegranzi B, Sax H, Dharan S, Pessoa-Silva CL, Donaldson L, et al. Evidence-based model for hand transmission during patient care and the role of improved practices. Lancet Infect Dis. 2006;6(10):641-52.

10. Goel S, Tank R, Singh A, Khichi SK, Bypareddy R, Goyal P, et al. Are doctor's hands contributing in spreading nosocomial pathogens? Rapid appraisal from a tertiary care health center of Northern India. Int J Res Med Sci. 2017; 4(6):1978-82.

11. Gould DJ, Drey NS, Moralejo D, Grimshaw J, Chudleigh J. Interventions to improve hand hygiene compliance in patient care. J Hosp Infect. 2008;68(3): 193-202.

12. Karabey S, Ay P, Derbentli S, Nakipoglu Y, Esen F. Handwashing frequencies in an intensive care unit. J Hosp Infect. 2002;50(1):36-41.

13. Amazian $K$, Abdelmoumène $T$, Sekkat $S$, Terzaki S, Njah M, Dhidah L, et al. Multicentre study on hand hygiene facilities and practice in the Mediterranean area: results from the NosoMed Network. J Hosp Infect. 2006; 62(3):311-8.

14. World Health Organization. Patient safety, a world alliance for safer health care. Suggested key messages to use. http://www.who.int/gpsc/5may/resources/ slcyh_briefing-kit_key-messages.pdf?ua=1.

15. Pittet D, Allegranzi B, Storr J. The WHO Clean Care is Safer Care programme: field-testing to enhance sustainability and spread of hand hygiene improvements. J Infect Public Health. 2008;1(1):4-10.

16. Pfäfflin F, Tufa TB, Getachew M, Nigussie T, Schönfeld A, Häussinger D, et al. Implementation of the $\mathrm{WHO}$ multimodal hand hygiene improvement strategy in a University Hospital in Central Ethiopia. Antimicrob Resist Infect Control. 2017:6:3

17. Santosaningsih D, Erikawati D, Santoso S, Noorhamdani N, Ratridewi I, Candradikusuma D, et al. Intervening with healthcare workers' hand hygiene compliance, knowledge, and perception in a limited-resource hospital in Indonesia: a randomized controlled trial study. Antimicrob Resist Infect Control. 2017:6:23.

18. Farhoudi F, Sanaei Dashti A, Hoshangi Davani M, Ghalebi N, Sajadi G, Taghizadeh R. Impact of WHO hand hygiene improvement program implementation: a quasi-experimental trial. BioMed Res Int. 2016;2016: 7026169.

19. Lee SS, Park SJ, Chung MJ, Lee JH, Kang HJ, Lee J, et al. Improved hand hygiene compliance is associated with the change of perception toward hand hygiene among medical personnel. Infect Chemother. 2014;46(3):165-71.

20. Mahfouz AA, Al-Zaydani IA, Abdelaziz AO, El-Gamal MN, Assiri AM. Changes in hand hygiene compliance after a multimodal intervention among healthcare workers from intensive care units in Southwestern Saudi Arabia. J Epidemiol Glob Health. 2014;4(4):315-21.

21. Mestre G, Berbel C, Tortajada P, Alarcia M, Coca R, Gallemi G, et al. "The $3 / 3$ strategy": a successful multifaceted hospital wide hand hygiene intervention based on WHO and continuous quality improvement methodology. PLOS ONE. 2012;7(10):e47200.

22. Monistrol O, Calbo E, Riera M, Nicolás C, Font R, Freixas N, et al. Impact of a hand hygiene educational programme on hospital-acquired infections in medical wards. Clin Microbiol Infect Off Publ Eur Soc Clin Microbiol Infect Dis. 2012;18(12):1212-8.

23. Allegranzi B, Sax H, Bengaly L, Richet H, Minta DK, Chraiti M, et al. Successful implementation of the World Health Organization hand hygiene improvement strategy in a referral hospital in Mali. Africa. Infect Control Hosp Epidemiol. 2010;31(2):133-41.

24. Sax H, Allegranzi B, Chraïti M-N, Boyce J, Larson E, Pittet D. The World Health Organization hand hygiene observation method. Am J Infect Control. 2009;37(10):827-34.

25. Wold Health Organization. A guide to the implementation of the WHO multimodal hand hygiene improvement strategy. Geneva 2009. http://www. who.int/gpsc/5may/Guide_to_Implementation.pdf.

26. Wold Health Organization. Tools for training and education. Geneva 2009. http://www.who.int/gpsc/5may/tools/training_education/en/.

27. World Health Organization. Guidelines on hand hygiene in health care. Geneva: WHO; 2009. http://www.who.int/gpsc/5may/tools/9789241597906/en/.

28. Martín-Madrazo C, Cañada-Dorado A, Salinero-Fort MA, Abanades-Herranz JC, Arnal-Selfa R, García-Ferradal I, et al. Effectiveness of a training programme to improve hand hygiene compliance in primary healthcare. BMC Public Health. 2009;9:469.

29. Sax H, Allegranzi B, Uçkay I, Larson E, Boyce J, Pittet D. "My five moments for hand hygiene": a user-centred design approach to understand, train, monitor and report hand hygiene. J Hosp Infect. 2007:67(1):9-21.

30. Pittet D, Mourouga P, Perneger TV. Compliance with handwashing in a teaching hospital. Infection Control Program. Ann Intern Med. 1999;130(2):126-30.

31. World Health Organization. Hand hygiene technical reference manual. Geneva 2009. http://www.who.int/gpsc/5may/tools/evaluation_feedback/ en/index.html.

32. Mu X, Xu Y, Yang T, Zhang J, Wang C, Liu W, et al. Improving hand hygiene compliance among healthcare workers: an intervention study in a Hospital in Guizhou Province. China. Braz J Infect Dis Off Publ Braz Soc Infect Dis. 2016;20(5):413-8.

33. Salama MF, Jamal WY, Mousa HA, Al-Abdulghani KA, Rotimi VO. The effect of hand hygiene compliance on hospital-acquired infections in an ICU setting in a Kuwaiti teaching hospital. J Infect Public Health. 2013;6(1):27-34.

34. Abela N, Borg MA. Impact on hand hygiene compliance following migration to a new hospital with improved resources and the sequential introduction of World Health Organization recommendations. Am J Infect Control. 2012;40(8):737-41.

35. von Lengerke T, Lutze B, Krauth C, Lange K, Stahmeyer JT, Chaberny IF. Promoting hand hygiene compliance. Dtsch Arzteblatt Int. 2017;114(3):29-36.

36. Ye L-P, Zhang X-P, Lai X-Q. Does hospital ownership influence hand hygiene compliance? J Huazhong Univ Sci Technol Med Sci Hua Zhong Ke Ji Xue Xue Bao Yi Xue Ying Wen Ban Huazhong Keji Daxue Xuebao Yixue Yingdewen Ban. 2017;37(5):787-94.

37. Pittet D, Hugonnet $S$, Harbarth S, Mourouga P, Sauvan V, Touveneau S, et al. Effectiveness of a hospital-wide programme to improve compliance with hand hygiene. Infection Control Programme. Lancet Lond Engl. 2000; 356(9238):1307-12.

38. Lam BCC, Lee J, Lau YL. Hand hygiene practices in a neonatal intensive care unit: a multimodal intervention and impact on nosocomial infection. Pediatrics. 2004;114(5):e565-71.

39. Donowitz LG. Handwashing technique in a pediatric intensive care unit. Am J Dis Child 1960. 1987;141(6):683-5.

40. Squires JE, Linklater S, Grimshaw JM, Graham ID, Sullivan K, Bruce N, et al. Understanding practice: factors that influence physician hand hygiene compliance. Infect Control Amp Hosp Epidemiol. 2014:35(12):1511-20.

41. Larson E, Killien M. Factors influencing handwashing behavior of patient care personnel. Am J Infect Control. 1982;10(3):93-9.

42. Smiddy MP, O' Connell R, Creedon SA. Systematic qualitative literature review of health care workers' compliance with hand hygiene guidelines. Am J Infect Control. 2015;43(3):269-74.

43. Pittet D, Simon A, Hugonnet S, Pessoa-Silva CL, Sauvan V, Perneger TV. Hand hygiene among physicians: performance, beliefs, and perceptions. Ann Intern Med. 2004;141(1):1-8.

44. Erasmus V, Brouwer W, van Beeck EF, Oenema A, Daha TJ, Richardus JH, et al. A qualitative exploration of reasons for poor hand hygiene among hospital workers: lack of positive role models and of convincing evidence that hand hygiene prevents cross-infection. Infect Control Hosp Epidemiol. 2009;30(5):415-9.

45. Kingston LM, Slevin BL, O'Connell NH, Dunne CP. Attitudes and practices of Irish hospital-based physicians towards hand hygiene and hand rubbing using alcohol-based hand rub: a comparison between 2007 and 2015. J Hosp Infect. 2017:97(1):17-25. 
46. Lankford MG, Zembower TR, Trick WE, Hacek DM, Noskin GA, Peterson LR. Influence of role models and hospital design on the hand hygiene of health-care workers. Emerg Infect Dis. 2003;9(2):217-23.

47. Larson EL, Early E, Cloonan P, Sugrue S, Parides M. An organizational climate intervention associated with increased handwashing and decreased nosocomial infections. Behav Med Wash DC. 2000;26(1):14-22.

48. Shears P. Poverty and infection in the developing world: healthcare-related infections and infection control in the tropics. J Hosp Infect. 2007;67(3):217-24.

49. World Health Organization. Health system profile Tunisia. Regional office for the Eastern Mediterranean, WHO 2006. http://apps.who.int/medicinedocs/ documents/s17312e/s17312e.pdf.

50. Dorsey ST, Cydulka RK, Emerman CL. Is handwashing teachable?: failure to improve handwashing behavior in an urban emergency department. Acad Emerg Med Off J Soc Acad Emerg Med. 1996;3(4):360-5.

51. Muto CA, Sistrom MG, Farr BM. Hand hygiene rates unaffected by installation of dispensers of a rapidly acting hand antiseptic. Am J Infect Control. 2000;28(3):273-6.

\section{Publisher's Note}

Springer Nature remains neutral with regard to jurisdictional claims in published maps and institutional affiliations.

\section{Submit your manuscript to a SpringerOpen ${ }^{\circ}$ journal and benefit from:}

- Convenient online submission

- Rigorous peer review

- Open access: articles freely available online

High visibility within the field

- Retaining the copyright to your article

Submit your next manuscript at $\boldsymbol{\wedge}$ springeropen.com 